\title{
Association between stress and eating behaviour among nurses in Hospital Universiti Sains Malaysia
}

\author{
Nurul Hasanah Noor Mohd Sapian \& Juliana Shamsudin* \\ Nutrition and Dietetics Program, School of Health Sciences, Health Campus, Universiti \\ Sains Malaysia, 16150 Kubang Kerian, Kelantan, Malaysia.
}

\begin{abstract}
Introduction: Stress is a factor that may affect dietary behaviour among nurses, which can contribute to a risk of overweight or obesity in the future. The aim of this study was to determine the association between stress and eating behaviour among nurses at Hospital Universiti Sains Malaysia, Kelantan, Malaysia. Methods: A cross-sectional analysis was performed among 105 nurses (30-50 years of age; $84.8 \%$ females and $15.2 \%$ males) and participants were assessed using a selfadministered questionnaire consisting of socio-demographic data, body mass index (BMI), Perceived Stress Scale-10 (PSS-10), and the Dutch Eating Behaviour Questionnaire (DEBQ). Data were analysed using descriptive statistics and the associations were determined by Kruskal-Wallis Test. Results: Based on descriptive data, $73.3 \%$ of nurses $(n=77)$ were moderately stressed and $49.5 \%$ had normal BMI ( $n=52)$. Furthermore, according to three eating domains, the emotional eating score was the highest $(30.0 \pm 16.0)$. An association was found between emotional eating $\left[\chi^{2}(2)=10.305, p=0.006\right]$, while external eating $\left[\chi^{2}(2)=5.103, p=0.078\right]$, and restrained eating $\left[\chi^{2}(2)=2.335, p=0.311\right]$ did not display a significant difference. The Bonferroni test was further used and there was a significant difference between low and moderate stress levels only $(p<0.01)$, while others were not significantly different (low-high and moderate-high) $(p>0.05)$. The results showed that nurses in the low stress group had lower scores of emotional eating behaviour than nurses with moderate stress levels. Conclusion: Stress has an impact on emotional eating behaviour and more research is needed to fully understand this link.
\end{abstract}

Keywords: stress, eating behaviour, nurses

\section{INTRODUCTION}

Nursing is a health science profession that plays an important role in management of patient care in hospitals, clinics, institutions or even in the community. According to statistics, it was reported that there is a total of 74,788 registered nurses in Malaysia under the Ministry of Health, not including community and dental nurses (WHO, 2014). Nursing is considered to be an exceptionally difficult occupation compared to other professions because it is highly stressful (Chou, Li \& Hu, 2013). Nursing job stress is caused by a variety of factors including the need for patient care, professional issues, the workplace, and organisational policies and procedures (Bai \& Ravindran, 2019). In Malaysia, the prevalence of job stress among nurses was reported to be between $41.0 \%$ and 49.3\% (Emilia \& Noor Hassim, 2007;

\footnotetext{
*Corresponding author: Juliana Shamsudin

Nutrition and Dietetics Program, School of Health Sciences, Health Campus,

Universiti Sains Malaysia, 16150 Kubang Kerian, Kelantan, Malaysia.

Tel: 09-7677632; Fax: 09-7677515, E-mail address: juliana@usm.my

doi: https://doi.org/10.31246/mjn-2021-0038
} 
Ghawadra et al., 2019). In the meantime, $41.2 \%$ of Australian nurses reported being stressed at work (Maharaj, Lees \& Lal, 2019). Furthermore, a study from Iran reported that the prevalence of job stress among nurses has been reported to be high, at 90.0\% (Gheshlagh et al., 2017).

Stress is defined as the body and mind's attempt to adapt to a changing environment, or in other words, stress is the internal response to external events (Johan, Sarwar \& Majeed, 2017). Most notably, uncontrollable stress changes eating habits and increases consumption of hyperpalatable foods, particularly those high in fat, sugar, or salt (Yau \& Potenza, 2013). Moreover, stress can lead to an increase in the consumption of high-fat snacks and fast foods, as well as a lower intake of energy from carbohydrates (Barrington et al. 2014). In the long run, this can promote weight gain and body fat mass, increasing the risk of obesity among nurses (Bowman \& Vinyard, 2004). Previous research has found a high prevalence of overweight and obesity among nurses due to dietary habit, especially skipping of meals and physical inactivity, which can increase the risk of poor health conditions such as diabetes, cardiovascular disease, high blood pressure, and high cholesterol. Aside from a hectic work schedule, a sedentary lifestyle and a lack of physical activity can contribute to weight gain or unhealthy food choices (Aryee et al., 2013).

Thus, it is essential to understand the prevalence of stress and its association with eating behaviour among nurses, as it is an important issue to explore in order to overcome and develop appropriate interventions or potential strategies for obesity prevention. The objective of this study was, therefore, to determine the association between stress and eating behaviour among nurses in Hospital Universiti Sains Malaysia, Kelantan, Malaysia.

\section{MATERIAL AND METHODS}

\section{Study population}

This research was a cross-sectional study performed between January 2019 and March 2019. A cross-sectional study design was used to (1) examine the level of stress and eating behaviour; (2) determine the status of body mass index (BMI); (3) determine the association between stress and eating behaviour among nurses at Hospital Universiti Sains Malaysia. The study setting was at Hospital Universiti Sains Malaysia, a teaching hospital in the Northeastern state of Kelantan, Malaysia.

Nurses who worked at the Hospital Universiti Sains Malaysia's inpatient wards (13 wards), clinics, and other departments (dental, oncology, radiotherapy, psychiatric and haemodialysis units) were eligible for the study if they were present on the day of data collection, interested in participating, and could read and understand Bahasa Malaysia. The exclusion criteria were trainee and student nurses.

\section{Sampling method}

Convenience sampling method was used to recruit all eligible nurses working in Hospital Universiti Sains Malaysia. The sample size needed for this study was calculated based on the formula by Daniel (1999) $n=\frac{Z^{2} P(1-P)}{d^{2}} \quad(n=$ sample size, $Z=Z$ statistic for a level of confidence at $95 \%$, $P=$ expected prevalence stress among nurses, $d=$ precision) with the value of $P$ being equal to $93.4 \%$ (Mwinga \& Mugala, 2015). The calculation considered a $20 \%$ drop-out rate in the study. Accordingly, the total participants required for this study was 114 .

\section{Measuring tools}

The measurement tool used in this study was a self-administered questionnaire. The questionnaire consisted of four parts (A, B, C and D) as described below. 
Part A (demographic data)

Part A contains questions related to the demographic data that included information on age, gender, ethnicity, and marital status.

\section{Part B (anthropometric data)}

Part B comprises anthropometric data which included weight, height, and BMI. In order to determine BMI, the weight and height of participants were collected using the dial mechanical weighing scale with height rod that was located in each department, ward, or clinic at the hospital. The current weight and height were self-recorded based on the average of two measurement readings. For weight measurement, participants were advised to empty their pockets before, and reading was recorded to the nearest 0.1 $\mathrm{kg}$. Meanwhile, for height measurement, participants were instructed to remove their shoes or others related footwear, stand upright and look forward with both hands at the sides. The measurement of height was recorded to the nearest 0.1 $\mathrm{cm}$. Subsequently, BMI was calculated using the formula of BMI = weight $(\mathrm{kg}) /$ height $(\mathrm{m})^{2}$. Based on the World Health Organization (WHO) classification, BMI was then classified as underweight, normal, overweight, or obesity (WHO, 2000).

\section{Part C (Perceived Stress Scale-10)}

In Part C, stress level was determined using the Perceived Stress Scale-10 (PSS10). The Malay version of the PSS-10 is a reliable and accurate measure of stress among nurses in Malaysia (Sukhvinder Singh, Noor Hassim \& Krishna Gopal, 2015). The PSS-10 has ten items on a 5 -Likert scale and the scale was scored as 0 =never, 1 =almost never, 2 =sometimes, 3 =fairly often, and 4=very often. Out of the ten items, there were four positive items (items 4, 5, 7, and 8) that were graded in reverse $(0=$ very often, $1=$ fairy often, 2= sometimes, 3=almost never,
$4=$ never). The total score ranged from 0 to 40 , with a higher score indicating a higher level of perceived stress $(0-13=1$ low, 14-26=moderate, and 27-40=high). The Cronbach's alpha coefficient value was 0.82 for the first factor (six items) and 0.72 for the second factor (four items). The overall alpha value was 0.63 , demonstrating a satisfactory level of validity and reliability in assessing stress perception among nurses in Malaysia (Sukhvinder Singh, Noor Hassim \& Krishna Gopal, 2015). Permission to use the Malay versions of the PSS-10 was granted by the researchers who translated and validated these survey instruments.

\section{Part D (Dutch Eating Behaviour Questionnaire)}

The final section of part D involved using the Dutch Eating Behaviour Questionnaire (DEBQ) to determine eating behaviours. DEBQ is a 33-item self-reported questionnaire designed to determine eating styles that can contribute to or slow the occurrence of overweight. It consists of three scales: emotional (13 items), external (ten items), and restrained eating (ten items). Emotional eating was defined as eating in response to a negative emotion; external eating was defined as eating in response to the appearance of foods; and restrained eating was defined as an effort to avoid eating due to weight concerns (Van Strien et al., 1986). However, according to Subramaniam and colleagues, three items (items 21, 27 , and 14) were removed from the Malay version of the DEBQ due to low reliability coefficient values (Subramaniam et al., 2017). Thus, in total, only 30 items were used in the DEBQ Malay version, which was reported as a suitable instrument to be used to identify eating behaviours among adult Malaysians due to good construction validity and reliability. The internal consistency for emotional 
eating scale, external eating scale, and restrained eating scale were $0.914,0.819$, and 0.856, respectively (Subramaniam et al., 2017). All items must be completed on the basis of the Likert scale ( $1=$ never, 2=seldom, 3=sometimes, 4=often, and $5=$ very often). A higher total score indicated a greater tendency for poor eating behaviours. The researchers that translated and validated the DEBQ gave permission to use the Malay versions of these survey instruments.

\section{Data collection procedures}

After receiving ethical approval from the Ethics Committee of Universiti Sains Malaysia (USM/JEPeM/18100522), the researcher began collecting data by meeting with the participants. The purpose of the study, procedures, benefits, and potential risks of participating in this study were all explained to the participants. All eligible participants provided informed consent prior to the survey. Participants' confidentiality was guaranteed, and they could withdraw from the study at any time with no negative effects.

The participants completed a fourpart questionnaire that took about 20 minutes. The researchers collected the questionnaire from the participants a week later to give them sufficient time to complete it. The hypothesis was that there is an association between stress and eating behaviour among nurses at Hospital Universiti Sains Malaysia.

\section{Data analysis}

The analysis was carried out using the SPSS (version 24, SPSS Inc, Chicago, IL, USA) statistical software. The ShapiroWilk Test was used to determine if the distribution was normal. Participants' socio-demographic characteristics were summarised using descriptive data. Based on normality distribution, numerical data were presented as mean (standard deviation, $S D$ ) or median (interquartile range, $I Q R)$, while categorical data were presented as frequency and percentage. The association between stress and eating behaviour was evaluated using the Kruskal-Wallis Test. Statistical significance was determined at $p<0.05$.

\section{RESULTS}

\section{Demographic characteristics of study groups}

Prior to the study, there was a total of 114 participants, but nine were excluded due to incomplete questionnaires. Finally, only 105 participants completed the study. Females ( $n=89,84.8 \%)$ and Malays ( $n=103,98.1 \%$ ) made up the majority of the participants. Furthermore, majority of the participants $(n=78$, or $74.3 \%$ ) were married, followed by $21.0 \%(n=22)$ who were single and $4.8 \%(n=5)$ who were divorced.

Table 1. Demographic characteristics of participants $(n=105)$

\begin{tabular}{lc}
\hline \multicolumn{1}{c}{ Characteristics } & $n(\%)$ \\
\hline Age & $38(36.2)$ \\
$<30$ years & $42(40.0)$ \\
30-39 years & $16(15.2)$ \\
40-49 years & $9(8.6)$ \\
$>$ >50 years & \\
Gender & $16(15.2)$ \\
Male & $89(84.8)$ \\
Female & \\
Ethnic & $103(98.1)$ \\
Malay & $2(1.9)$ \\
Non-Malay & \\
Marital Status & $22(21.0)$ \\
Single & $78(74.3)$ \\
Married & $5(4.8)$ \\
Divorced & \\
Body Mass Index $\left(\mathrm{BMI}^{2}\right)$ & $5(4.8)$ \\
Underweight $\left(<18.5 \mathrm{kgm}^{-2}\right)$ & $52(49.5)$ \\
Normal $\left(18.5-24.9 \mathrm{kgm}^{-2}\right)$ & $33(31.4)$ \\
Overweight $\left(25-29.9 \mathrm{kgm}^{-2}\right)$ & $15(14.3)$ \\
Obese $\left(>29.9 \mathrm{kgm}^{-2}\right)$ &
\end{tabular}

According to the WHO classification, approximately $49.5 \%$ of participants 
$(n=52)$ were in the normal body weight category, followed by overweight ( $n=33$, $31.4 \%)$, obese $(n=15,14.3 \%)$, and underweight $(n=5,4.8 \%)$ (Table 1$)$.

\section{Stress level among nurses}

Table 2 shows the perceived stress score for participants classified as low, moderate, or high stress levels. Most nurses reported moderate stress levels $(n=77,73.3 \%)$, followed by low stress levels $(n=26,24.8 \%)$, and high stress levels $(n=2,1.9 \%)$. In the meantime, the overall mean total score was 16.1 $(S D=4.5)$.

Table 2. Stress level among participants $(n=105)$

\begin{tabular}{lcc}
\hline \multicolumn{1}{c}{ Characteristics } & $n(\%)$ & Range \\
\hline Level of stress & & \\
Low & $26(24.8)$ & $4.0-13.0$ \\
Moderate & $77(73.3)$ & $14.0-26.0$ \\
High & $2(1.9)$ & $27.0-28.0$ \\
Overall PSS score & $16.1(4.5)$ & - \\
\hline
\end{tabular}

Perceived Stress Score (PSS): 0-13=low, 14-26=moderate, and 27-40=high

\section{Eating behaviour among nurses}

Table 3 shows the scores of eating behaviours in three domains: emotional, external, and restrained among participants. The results indicated that total emotional eating score (30 points, $I Q R=16)$ was higher than external eating score (27 points, $S D=5.8$ ) and restrained eating behaviour score $(25$ points, $S D=7.2)$.

\section{Association between stress and eating behaviour}

Kruskal-Wallis Test showed that the stress level of participants (low, moderate, or high) differed significantly from that of emotional eating behaviour only $\left[\chi^{2}(2)=10.305, p=0.006\right]$. In the meantime, both external eating $\left[\chi^{2}(2)=5.103, p=0.078\right]$ and restrained eating $\left[\chi^{2}(2)=2.335, p=0.311\right]$ did not show a significant difference (Table 4).

Specifically, based on the post-hoc Bonferroni correction test, there was a significant difference between low and moderate stress levels with emotional eating score $(p<0.01)$ only, while others were not significantly different $(p>0.05)$. It has been shown that nurses in the low stress category had lower scores of emotional eating behaviour compared to nurses with moderate stress level.

\section{DISCUSSION}

This current study is important to find an association between stress level and eating behaviour among nurses since stress may promote unhealthy eating behaviours, and this can lead to many health complications such as obesity and cardiovascular risk. Majority of the participants in this study were females, with the remaining participants being males. Due to the nature of this profession, which is usually associated with females, there was naturally a higher proportion of female participants (Pudney \& Shields, 2000). Furthermore, the prevalences of overweight (32.4\%) and

Table 3. Eating behaviour scores of participants $(n=105)$

\begin{tabular}{lccc}
\hline $\begin{array}{c}\text { Eating behaviour } \\
\text { categories }\end{array}$ & Mean $\pm S D$ & Median (IQR) & Range \\
\hline Emotional & & $30.0(16.0)$ & $13.0-57.0$ \\
External & $27.0 \pm 5.8$ & & $15.0-40.0$ \\
Restrained & $25.0 \pm 7.2$ & & $9.0-41.0$ \\
\hline
\end{tabular}


Table 4. Comparison of eating behaviour score categories with stress level among participants in Hospital Universiti Sains Malaysia $(n=105)$

\begin{tabular}{ccccc}
\hline Parameter & Stress level & Median (IQR) & $\begin{array}{c}\text { Chi-square } \\
\text { statistic (df) }\end{array}$ & p-value $^{+}$ \\
\hline Emotional score & Low & $23(16.8)$ & $10.305(2)$ & $0.006^{*}$ \\
& Moderate & $33(14.0)$ & & \\
External score & High & $37(\mathrm{NA})$ & & \multirow{2}{*}{0.078} \\
& Low & $25(6.5)$ & $5.103(2)$ & \\
& Moderate & $28(8.5)$ & & 0.311 \\
Restrained score & High & $27(\mathrm{NA})$ & & \\
& Low & $22(12.5)$ & $2.335(2)$ & \\
& Moderate & $26(9.5)$ & & \\
& High & $30(\mathrm{NA})$ & & \\
\hline
\end{tabular}

${ }^{+}$Tested using Kruskal-Wallis Test, significant at $p<0.05$

*Post-hoc with Bonferroni's correction: low vs. moderate $(p<0.01)$, low vs. high $(p>0.05)$, moderate vs. high $(p>0.05)$

obesity (14.3\%) were high among nurses in this study, which was consistent with a study conducted among registered Malaysian nurses (overweight 33.5\% and obese $17.1 \%$ ) (Coomarasamy, Wint $\&$ Sukumaran, 2015).

In terms of stress prevalence among nurses, the mean overall stress level was moderate, with the majority falling into this category (73.3\%). The prevalence was reportedly within the range according to a meta-analysis study from Iran at 6990\% (Gheshlagh et al., 2017), but higher in Zambian nurses at 93.4\% (Mwinga \& Mugala, 2015). When compared to other health workers, the nursing profession appears to be more stressful (Yeboah et al., 2014). In addition, nurses working in public hospitals in Thailand are more stressed than those working in private hospitals, according to a study by Tyson \& Pongruengphant (2004).

The greater number of nurses experiencing moderate stress may be caused by many factors such as patient, occupational, organisational or personal factors (Bai \& Ravindran, 2019). In addition, other possible explanations for this variation may be different countries, hospital settings either teaching or non-teaching hospital, and convenience sampling that can increase in inaccuracy. The causes of job stress in nurses according to a previous study is the job itself. It was reported that heavy workload, repetitive work, and poor working environment were among the factors that trigger stress among nurses, especially in the public health services in Malaysia (Beh \& Loo, 2012). A most significant finding was that job factors, rather than demographic factors, are more involved in job stress (Najimi, Goudarzi \& Sharifirad, 2012). However, in this study, factors that led to stress among nurses were not determined.

In this study, three domains of eating behaviours were assessed: emotional, external, and restrained. Stress was found to have a significant relationship with emotional eating behaviour in this study, but not in the other domains. This contrasts with findings of a Saudi Arabian study, which found that stress was positively associated with all three domains of emotional, external, and restrained eating (Almajwal, 2016). Prior study also found that the associations between stress and eating behaviours were usually different in each of the eating behavioural domains and were gender-influenced (Ohara et al., 2019). 
The different outcomes of the studies may be due to the different versions and items used to assess psychological stress and eating behaviours. In terms of psychological stress, the current study used the Malay version of PSS and had ten items compared to the previous study that used the English version that consisted of four items only. Meanwhile, for eating behaviour, the tool used was dietary eating behaviour in Malay version that consisted of 30 items compared to the previous study that used the original English version that consisted of 33 items in the questionnaire (Almajwal, 2016).

This study found that nurses with moderate stress had higher scores of eating behaviours relative to those with low stress. Higher scores of eating behaviours indicates poor eating behaviours. Emotional conditions, such as anxiety, depression and sadness, stimulates dietary behaviours that do not conform to dietary guidelines (e.g. increased food intakes or poor food choices) (Devonport, Nicholls \& Fullerton, 2019). Furthermore, previous research has shown that stressed emotional eaters consume more sweets, high-fat foods, as well as energy-dense meals, than unstressed and non-emotional eaters. Besides that, stressed workers are more likely to develop negative eating habits such as overeating and gaining weight (Nishitani \& Sakakibara, 2007). This will exacerbate overweight or obesity issues, having an impact on nurses' health and wellbeing. However, this study did not assess the dietary intake of nurses.

The current research included analysis of classification of body weight or BMI with stress level, which might provide some additional information as an example, there was a similar pattern showing that the majority of participants in each BMI category (underweight, normal, overweight and obesity) had a moderate stress level. A meta-analysis study to determine the association between BMI with stress reported that stress was associated with increasing BMI, which was not consistent with the current study. The reason for differences might be due to the complexity of how humans react towards stress with foods because some may eat more or less as a response to stress (Wardle et al., 2011), therefore this may lead to weight problems either under- or overweight. In addition, self-reported weight and height may be biased and therefore needs precaution in its interpretation. Importantly, given the scarcity of published research on emotional eating, its impact on the stress-eating relationship would require further investigation.

Meanwhile, the lack of significant differences in terms of stress and external eating behaviour could be attributed to different backgrounds of environmental factors, as this study drew nurses from a variety of backgrounds, including inpatient, outpatient, and dental nurses. This was supported by the fact that external eating behaviour is defined as a shift in attitude towards environmental factor cues during times of stress, and people are compelled to eat (Almajwal, 2016). The wide differences in environmental factors of a diverse working environment may give rise to this pattern of results. In addition, previous studies have shown that although nurses realised they could face problems of overweight or obesity, many have not practised weight management behaviours (Zapka et al., 2009). This may explain why there were no significant differences in stress with respect to restricted eating behaviour. As mentioned earlier, restrained eating behaviour is an attempt to refrain from eating because of concerns about weight gain.

There were some limitations in this study. This was a cross-sectional study 
that prevented the possibility of assessing causality. In addition, this study also involved nurses from all departments, either inpatient or outpatient setting, which could confound the findings since other factors, such as work shifts, may influence outcome. Aside from that, the participants' dietary intakes were not measured and analysed in this study, while the measurements of weight and height were self-recorded by the nurses.

Despite these limitations, this current study added knowledge by providing information on the current prevalence of stress, eating behaviours, BMI and the significant association between stress and emotional eating behaviour among nurses at Hospital Universiti Sains Malaysia. It is necessary to evaluate the level of stress among nurses because further research are needed on appropriate interventions to reduce the burden of health and obesity among this population.

For nurses, it is important to have better stress management in the future because this is essential to their mental wellbeing. The hospital nursing management should take proactive actions by designing tailored stress management programme, provide continuous psychological support system for the nurses, appreciate the contributions of nurses, and take responsibility in the mental health of their staff by providing them with a conducive working environment that is less stressful (Salilih \& Abajobir, 2014). In terms of promotion of healthy eating, nurses can also receive individual dietary advice from the hospital dietitians to improve their eating practices in order to reduce stress-related over-eating. More research is needed to confirm the link between stress and eating behaviour by taking into consideration other factors, such as shift works, disease, working place (Salilih \& Abajobir, 2014), years of work experience and total working hours.

\section{CONCLUSION}

In conclusion, only emotional eating was linked to stress in nurses. The other domains - external and restrained eating - had no links to stress. As a result, drawing a firm conclusion about the relationship between stress and eating behaviour in general is difficult and requires further investigation.

\section{Acknowledgements}

We value the involvement of nurses from Hospital Universiti Sains Malaysia who participated in this study. The authors wish to recognise the approval of the Universiti Sains Malaysia Ethics Committee for this study.

\section{Authors' contributions}

NHNMS, conducted the study, data analysis, and interpretation of the data with the support from JS; JS, helped supervise the study, prepared the draft of the manuscript, and reviewed the manuscript. All authors approved the final manuscript.

\section{Conflict of interest}

The authors declare that they have no conflicting financial or non-financial interests in this study.

\section{References}

Almajwal AM (2016). Stress, shift duty, and eating behavior among nurses in Central Saudi Arabia. Saudi Med J 37(2):191-198. https:// doi.org/10.15537/smj.2016.2.13060

Aryee P, Helegbe G, Baah B, Sarfo-Asante R \& Quist-Therson R (2013). Prevalence and risk factors for overweight and obesity among nurses in the Tamale Metropolis of Ghana. $J$ Medical Biomed Sci 2(4):13-23. https://doi. org/10.4314/jmbs.v2i4.3

Bai JH \& Ravindran V (2019). Job stress among nurses. IJCNE 20(2):92-96. https://doi. org/10.4103/ijcn.ijcn_11_20

Barrington WE, Beresford SAA, Mcgregor BA $\&$ White E (2014). Perceived stress and eating behaviors by sex, obesity status, and stress vulnerability: findings from the Vitamins and Lifestyle (VITAL) study. J Acad Nutr Diet 114(11):1791-1799. https://doi. org/10.1016/j.jand.2014.03.015 
Beh LS \& Loo LH (2012). Job stress and coping mechanisms among nursing staff in public health services. IJARBSS 2(7):131-176.

Bowman SA \& Vinyard BT (2004). Fast food consumption of U.S. adults: Impact on energy and nutrient intakes and overweight status. $J$ Am Coll Nutr 23(2):163-168. https://doi.org/ 1 $0.1080 / 07315724.2004 .10719357$

Chou LP, Li CY \& Hu SC (2013). Job stress and burnout in hospitalemployees: comparisons of differentmedical professions in a regional hospital in Taiwan. BMJ Open 4:1-7.

Coomarasamy JD, Wint N \& Sukumaran S (2015). Prevalence of obesity and daily lifestyles of the registered nurses in Malaysia. IJIAS 7(3):12021208. http:/ / www.ijias.issr-journals.org/

Daniel WW (1999). Biostatistics: A Foundationfor Analysis in the Health Sciences. 7th edition. New York: John Wiley \& Sons.

Devonport TJ, Nicholls W \& Fullerton C (2019). A systematic review of the association between emotions and eating behaviour in normal and overweight adult populations. $J$ Health Psychol 24(1):3-24. https://doi. org/10.1177/1359105317697813

Emilia Z \& Noor Hassim I (2007). Work-related stress and coping: a survey on medical and surgical nurses in a Malaysian teaching hospital. Jurnal Kesihatan Masyarakat 13(1):55-66.

Ghawadra SF, Abdullah KL, Choo WY \& Phang CK (2019). Psychological distress and its association with job satisfaction among nurses in a teaching hospital. J Clin Nurs 28:40874097. https://doi.org/10.1111/jocn.14993

Gheshlagh RG, Parizad N, Dalvand S, Zare M, Farajzadeh M, Karam M \& Sayehmiri K (2017). The prevalence of job stress among nurses in Iran: A meta-analysis study. Nurs Midwifery Stud 6:143-148. https://doi.org/10.4103/ nms.nms_33_17

Johan S, Sarwar H \& Majeed I (2017). To identify the causes of stress among nurses working in intensive care unit of Ittefaq Hospital Lahore. Int $J$ Soc Sc Manage 4(2):96-109. https://doi. org/10.3126/ijssm.v4i2.17159

Maharaj S, Lees T \& Lal S (2019). Prevalence and risk factors of depression, anxiety, and stress in a cohort of Australian nurses. Int $J$ Environ Res Public Health 16(61):1-10 https://doi. org/10.3390/ijerph16010061
Mwinga C \& Mugala D (2015). Prevalence and causes of stress among nurses at Ndola Central Hospital - A nurses perspective. IJNRHN 2(3):158-165.

Najimi A, Goudarzi AM \& Sharifirad G (2012). Causes of job stress in nurses: A crosssectional study. IJNMR 17(4):301-305.

Nishitani N \& Sakakibara H (2007). Relationship of BMI increase to eating behavior and job stress in a 2-year cohort study of non-obese male Japanese workers. Obes Res Clin Pract 1(3):179-185. https://doi.org/10.1016/j. orcp.2007.06.002

Ohara K, Mase T, Kouda K, Miyawaki C, Momoi K, Fujitani T, Fujita Y \& Nakamura H (2019). Association of anthropometric status, perceived stress, and personality traits with eating behavior in university students. Eat Weight Disord 24(3):521-531. https://doi. org/10.1007/s40519-018-00637-w

Pudney S \& Shields (2000). Gender, race, pay and promotion in the British nursing profession: Estimation of a generalized ordered probit model. J Appl Econ 15(4): 367-399. https://doi.org/10.1002/10991255 (200007/08) 15:4<367:: A I D JAE563>3.0.CO;2-Z

Salilih SZ \& Abajobir AA (2014). Work-Related Stress and Associated Factors Among Nurses Working in Public Hospitals of Addis Ababa, Ethiopia: A Cross-sectional Study. Workplace Health Saf 62(8):326-332.

Subramaniam K, Low W, Chinna K, Chin K \& Krishnaswamy S (2017). Psychometric properties of the Malay version of the Dutch Eating Behaviour Questionnaire (DEBQ) in a sample of Malaysian adults attending a health care facility. Malays J Med Sci 24(4): 64-73. https://doi.org/10.21315/mjms2017.24.4.8

Sukhvinder Singh S, Noor Hassim I \& Krishna Gopal R (2015). The Malay version of the Perceived Stress Scale (PSS)-10 is a reliable and valid measure for stress among nurses in Malaysia. Malays J Med Sci 22(6):26-31.

Tyson PD \& Pongruengphant R (2004). Fiveyear follow-up study of stress among nurses in public and private hospitals in Thailand. Int $J$ Nurs Stud 41(3):247-254. https://doi. org/10.1016/S0020-7489(03)00134-2 
Van Strien T, Frijters JE, Bergers GP \& Defares $P$ (1986). The Dutch Eating Behavior Questionnaire (DEBQ) for assessment of restrained, emotional, and external eating behavior. Int J Eat Disord 5:295-315. https:/ / doi.org/ 10.1007/BF02973988

Wardle J, Chida Y, Gibson EL, Whitaker KL \& Steptoe A (2011). Stress and adiposity: A meta-analysis of longitudinal studies. Obesity 19(4):771-778. https://doi.org/10.1038/ oby. 2010.241

WHO (2014). In: Human resources for health country profiles: Malaysia. World Health Organization. From: http://www.wpro.who. int/hrh/documents/publications / [Retrieved March 8 2021].

WHO (2000). In: WHO Consultation on Obesity (1999: Geneva, Switzerland) \& World Health Organization. Obesity : preventing and managing the global epidemic : report of a WHO consultation. World Health Organization. From: https://apps.who.int/iris/ handle/10665/42330 [Retrieved November 18 2021].
Yau YHC \& Potenza MN (2013). Stress and eating behaviors. Minerva Endocrinol 38(3):255-267.

Yeboah MA, Ansong MO, Antwi HA, Yiranbon E, Anyan F \& Gyebil F (2014). Determinants of workplace stress among healthcare professionals in Ghana : An empirical analysis. IJBSS 5(4):140-151.

Zapka JM, Lemon SC, Magner RP \& Hale J (2009). Lifestyle behaviours and weight among hospital-based nurses. J Nurs Manag 17(7): 853-860. https://doi.org/10.1111/j.13652834.2008.00923.x 